\title{
Could cannabidiol play a role in the treatment of chronic pain?
}

\section{Gerhard Nahler* \\ CIS GmbH, Kaiserstr, Austria}

Pain is the most common symptom reported by patients and a costly health care problem. Unfortunately, currently available analgesic medications and pain-modulating procedures are often limited by their efficacy and/or safety. Sooner or later, a high percentage of patients with chronic pain seek relief with opioids, widely recognized as the "gold standard" in pain control. However, they are not without problems as an overdose can induce pulmonary arrest, and paradoxically, opioids can induce hyperalgesia [1]. Some countries such as the US and Canada report an increasing death rate related to opiod- overdoses that reached 14.7 per 100,000 persons in 2014 [2].

When patients find insufficient pain relief with standard therapies, many of them turn to self medication with medical cannabis (marijuana) with $\Delta 9$-tetrahydrocannabinol (THC) being its main bioactive ingredient. Medical cannabis has, in fact, a long history of use as pain medication and is the primary reason for being smoked by patients. However, the use of medical cannabis (THC) is limited by its psychoactive and cognitive effects such as on memory or attention as well as the predominant delivery route (smoking), further to regulatory or legal constraints. In terms of pain reduction, a recent systematic review and meta-analysis of cannabinoids for medical use examined 28 randomized trials including 2454 patients with chronic pain [3]. Accordingly, compared with placebo, cannabinoids were associated with a greater reduction in pain $(37 \%$ vs. $31 \%)$ and a greater average reduction in numerical pain ratings $(-0.46)$. Whiting et al. [3] concluded that there was moderate evidence to support the use of cannabinoids for the treatment of chronic pain.

Observations of a clinically and statistically significant association between cannabis use and opioid prescription cessation or reductions as well as of improved quality of life deserve further comments [4]. A recent study found a 47 percentage point reduction in daily opioid dosages in medical cannabis patients relative to a mean increase in opioid use of 10.4 percentage points in the control group after 21 months [5]. Another recent meta-analysis concluded that the mean effective dose of morphine is 3.6 fold lower when administered in combination with THC [6]. Nonetheless, medical cannabis/marijuana, respectively THC, is far from being the ideal combination partner for reasons mentioned above.

Amazingly, the literature on the second most important cannabinoid in cannabis, cannabidiol (CBD) as a partner which does not demonstrate the shortcomings of unwanted psychoactive and cognitive effects or legal constraints is rather limited, despite that CBD has demonstrated analgesic effects in a number of various animal models [7-11]. In a few controlled clinical trials that compared a refined THC-rich extract with a CBD-rich extract and its combination (nabidiolex, Sativex ${ }^{\mathrm{m}}$ ) the CBD-rich extract, given at the same dose as in Sativex demonstrated weak analgesic effects. However, in Sativex the dose of CBD is nearly equal to that of THC. In order to be effective as monotherapy, CBD doses must be in the order of 300 to $600 \mathrm{mg}$ CBD per day which is more than ten times above an effective dose of THC. $\mathrm{CBD}$ was therefore under-dosed.

Of further interest is also the observation that combinations of CBD and morphine produced synergistic effects in reversing acetic acid-stimulated stretching behaviour in mice, although being less or ineffective in other pain models [12]. A small case series with CBD $(2 \mathrm{x}$ $200 \mathrm{mg} /$ day) that included five patients with chronic pain of various origins showed a reduction of opioids and improved subjective symptoms when CBD was added to the pain regimen [13]. A lower dose of $200 \mathrm{mg} /$ day was not clinically effective. The combination with opioids was not only safe but pain medication could be reduced by about 30 to $50 \%$. Unfortunately, the article was written in German and is therefore largely ignored by the English community.

Intriguingly, other publications point towards a potential role of $\mathrm{CBD}$ in mitigating addiction behaviours. CBD reduces morphinewithdrawal symptoms and reduces abstinence scores to a greater extent than THC alone, even in combination with THC [14]. In contrast to THC that potentiates heroin self-administration in rats, repeated CBD administration $(5-20 \mathrm{mg} / \mathrm{kg})$ did not alter heroin self-administration, but clearly inhibited cue-induced heroin-seeking behaviour with a prolonged effect, lasting two or more weeks after administration.

Although much more research is necessary, CBD could be a safe and well tolerated treatment option for combination with opioids and other standard pain medications or may show up as an alternative for treating chronic pain.

\section{References}

1. Kirkpatrick DR, McEntire DM, Hambsch ZJ, Kerfeld MJ, Smith TA, et al. (2015) Therapeutic basis of clinical pain modulation. Clin Transl Science 8: 848-856. [Crossref]

2. Rudd RA, Aleshire N, Zibbell JE, Gladden RM (2016) Increases in drug and opioid overdose deaths - United States, 2000-2014. Centers for Disease Control and Prevention, Morbidity and Mortality Weekly Report (MMWR) 64: 1378-1382.

3. Whiting PF, Wolff RF, Deshpande S, Di Nisio M, Duffy S, et al. (2015) Cannabinoids for Medical Use: A Systematic Review and Meta-analysis. JAMA 313: 2456-2473. [Crossref]

4. Lucas P (2017) Rationale for cannabis-based interventions in the opioid overdose crisis. Harm Reduction Journal 14: 58.

Correspondence to: Gerhard Nahler, CIS GmbH, Kaiserstr. 43, 1070 Wien, Austria, Tel: +43-1-5234015, Fax: +43-1-5234015-99, E-mail: cis-qa@aon.at

Received: January 10, 2018; Accepted: January 31, 2018; Published: Februaru 04,2018 
5. Vigil JM, Stith SS, Adams IM, Reeve AP (2017) Associations between medical cannabis and prescription opioid use in chronic pain patients: A preliminary cohort study. PLoS One 12: e0187795. [Crossref]

6. Nielsen S, Sabioni P, Trigo JM, Ware MA, Betz-Stablein BD, et al. (2017) Opioid-sparing effect of cannabinoids: a systematic review and meta-analysis. Neuropsychopharmacology 42: 1752-1765. [Crossref]

7. Ellis LD, Berrue F, Morash M, Achenbach JC, Hill J, et al. (2018) Comparison of cannabinoids with known analgesics using a novel high throughput zebrafish larval model of nociception. Behav Brain Res 337: 151-159. [Crossref]

8. Philpott HT, O'Brien M, McDougall JJ (2017) Attenuation of early phase inflammation by cannabidiol prevents pain and nerve damage in rat osteoarthritis. Pain 158: 2442 2451. [Crossref]

9. Hammell DC, Zhang LP, Ma F, Abshire SM, Mcllwrath SL, et al. (2016) Transdermal cannabidiol reduces inflammation and pain-related behaviours in a rat model of arthritis. Eur J Pain 20: 936-948. [Crossref]
10. Malfait AM, Gallily R, Sumariwalla PF, Malik AS, Andreakos E, et al. (2000) The nonpsychoactive cannabis constituent cannabidiol is an oral anti-arthritic therapeutic in murine collagen-induced arthritis. Proc Natl Acad Sci U S A 97: 9561-9566. [Crossref]

11. Formukong EA, Evans AT, Evans FJ (1988) Analgesic and antiinflammatory activity of constituents of Cannabis sativa L. Inflammation 12: 361-371. [Crossref]

12. Neelakantan H, Tallarida RJ, Reichenbach ZW, Tuma RF, Ward SJ, et al. (2015) Distinct interactions of cannabidiol and morphine in three nociceptive behavioral models in mice. Behav Pharmacol 26: 304-314. [Crossref]

13. Likar R (2016) Cannabidiol: Schmerzreduktion bei therapieresistenten Fällen. Universum Innere Medizin 08/16: 96-97.

14. Hurd YL, Yoon M, Manini AF, Hernandez S, Olmedo R, et al. (2015) Early phase in the development of cannabidiol as a treatment for addiction: opioid relapse takes initial center stage. Neurotherapeutics 12: 807-815. [Crossref]

Copyright: $\odot 2018$ Nahler G. This is an open-access article distributed under the terms of the Creative Commons Attribution License, which permits unrestricted use, distribution, and reproduction in any medium, provided the original author and source are credited. 